\title{
The Path of Sufism in the Novel Sastra Jendra Hayuningrat Pangruwating Diyu by Agus Sunyoto: a Psychosufistic Study
}

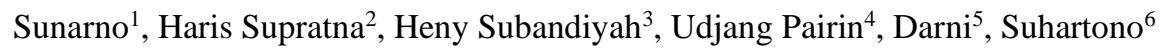 \\ \{Sunarno.19033@mhs.unesa.ac.id ${ }^{1}$, harissupratna@unesa.ac.id ${ }^{2}$, henysubandiyah@unesa.ac.id ${ }^{3}$, \\ udjangpairin@unesa.ac.id ${ }^{4}$, darni@unesa.ac.id ${ }^{5}$, suhartono@unesa.ac.id $\left.{ }^{6}\right\}$ \\ Universitas Negeri Surabaya, Indonesia ${ }^{123456}$
}

\begin{abstract}
This research focused on the main character Sudrun in Agus Sunyoto's novel, Sastra Jendra Hayuningrat Pangruwating Diyu. The novel tells the story of Sudrun's journey to get closer to Allah, and finally meeting people who guide him in finding that path. This research used psychosufistic theory and a qualitative descriptive approach to describe and explain the aspects concerned with Sudrun's spiritual journey. The research data were obtained by listening and taking notes. The purpose of this study was to describe the personality of the character Sudrun and his journey in getting closer to Allah.
\end{abstract}

Keywords: Salik, God, Sufism.

Jalan Salik dalam Novel Sastra Jendra Hayuningrat Pangruwating Diyu Karya Agus Sunyoto: Sebuah Kajian Psikosufistik

\begin{abstract}
Abstrak. Penelitian ini memfokuskan diri pada tokoh utama Sudrun dalam novel Sastra Jendra Hayuningrat Pangruwating Diyu karya Agus Sunyoto. Novel tersebut berkisah tentang perjalanan Sudrun mendekatkan diri kepada Allah, dan akhirnya bertemu dengan orang-orang yang membimbingnya dalam menemukan jalan tersebut. Penelitian ini menggunakan teori psikosufistik dan pendekatan deskriptif kualitatif untuk menguraikan, menggambarkan, dan memaparkan aspek-aspek yang bersangkutan dengan perjalanan spiritual Sudrun. Data penelitian diperoleh melalui cara menyimak dan mencatat. Tujuan penelitian ini adalah mendeskripsikan kepribadian tokoh Sudrun dan perjalanannya dalam mendekatkan diri kepada Allah.
\end{abstract}

Kata kunci: Salik, Tuhan, Tasawuf.

\section{Pendahuluan}

Membicarakan masalah tasawuf, Salik dan karakternya dalam sebuah novel merupakan hal yang sangat menarik karena ketiga hal tersebut sangat jarang kita temukan dalam karya sastra Indonesia. Karya sastra Indonesia cenderung didominasi oleh masalah asmara, politik, dan lokalitas daerah. Kesulitan kita dalam menemukan karya sastra yang merefleksikan 
tasawuf dan salik menjadikan hal tersebut menarik untuk dikaji dan diteliti. Salah satu karya sastra yang membicarakan masalah tasawuf ada pada karya-karya Agus Sunyoto (AS). Agus Sunyoto sangat produktif menulis karya sastra bernuansa tasawuf. Salah satu karya tersebut adalah Sastra Jendra Hayuningrat pangruwating Diyu (SJHPD). Novel tersebut sangat menarik karena menceritakan perjalanan seorang salik yang mencari dan mendekatkan diri kepada Allah. Dalam perjalanan tersebut dia bertemu dengan beberapa orang yang akhirnya menjadi guru pembimbingnya dan menuntunnya dalam menapaki jalan menuju menjadi seorang sufi. Selain itu, dia juga mengalami pengalaman-pengalaman spiritual yang luar biasa yang tidak bisa diterima oleh logika.

Salik adalah orang yang melakukan perjalanan spiritual dalam usaha mendekatkan diri kepada Allah dengan cara membersihkan diri dari sifat-sifat tercela. Menurut al-Jurjani salik adalah orang yang menempuh dan melewati maqamat dan menyusuri pengalaman rohani. [1] Menurut Syeh Muhammad Nafis al-Banjari salik adalah orang yang bersungguh-sungguh bermujahadah berbuat ibadah kepada Allah dengan melakukan riadah (latihan kejiwaan) dan mujahadah (menentang keinginan nafsu) serta mengamalkan wirid yang diijazahkan atau diajarkan kepadanya oleh gurunya tanpa mengurangi serta menyalahi apa yang disuruh oleh gurunya. [2] menurut Abdul Manan salik seperti yang digunakan oleh para ulama tasawuf adalah merujuk kepada pengertian perjalanan kerohanian seseorang menuju kepada Allah. Ia bukan bermaksud perjalanan fisikal yang terikat dengan masa dan tempat seperti yang dapat difahami dari pengertian bahasanya. la adalah perjalanan maknawi menempuh maqamat dan ahwal menuju kepada makrifatullah. Dengan kata lain, ia merupakan proses peningkatan tahap kebersihan jiwa dalam usaha pembersihan diri (tazkiyat an-nafs) untuk mencapai qurbah (kedekatan) dengan Allah serta mendapat keridaan-Nya. [3] Dari uraian di atas maka dapat disimpulkan bahwa salik adalah orang yang bersungguh-sungguh mendekatkan diri kepada Allah dengan cara membersihkan diri dan jiwa dengan mengamalkan wirid yang diperoleh dari gurunya. Kecenderungan salik seperti itu merupakan bagian dari kepribadian dan karakternya.

Berkaitan dengan masalah tasawuf, salik dan karakternya maka kita tidak bisa lepas dari psikologi sufistik (Psikosufistik). Psikosufistik merupakan suatu ilmu tentang tingkah laku manusia yang konsepnya dibangun atas dasar paradigm tasawuf yang berbasis kitab suci alqur'an dan sunnah nabi. Keilmuan mengenai psikologi sufistik selalu mengedepankan pengembangan potensi batin ke arah kesadaran psikologis untuk senantiasa dekat dengan Allah. [4]

Penelitian terdahulu yang relevan dengan penelitian ini adalah skripsi Abdur Rahman yang menyimpulkan bahwa terdapat tiga simbol utama Manunggaling Kawula Gusti dalam novel SJHPD, diantaranya hakikat nafs, pemahaman nafs muthma'innah, dan makna rabbraab'ul arbaab. Ketiganya secara esensial menegaskan batas antara hamba (kawula) dan Tuhan (gusti) dimana hamba hanya mampu mengakses gejala ketuhanan. [5] penelitian lainnya yaitu penelitian Tirsan tentang religiusitas dalam novel "Sastra Jendra Hayuningrat Pangruwating Diyu" yang meliputi unsur syariat, tareqat, hakikat, dan makrifat. [6] selanjutnya penelitian Hartati tentang pencarian kebenaran yang hasilnya yaitu bahwa dalam mencari kebenaran ada tiga tahap yaitu: tahap belajar dari iblis, perjalanan rohani, dan penemuan kebenaran. [7]

Penelitian di atas menghasilkan sebuah bentuk ajaran-ajaran tasawuf dan juga tahapantahapan dalam mencari kebenaran. Berbeda dengan penelitian ini yang berusaha membahas masalah tahapan yang harus dilalui seorang salik dalam usaha mendekatkan diri kepada Allah. Tahapan-tahapan inilah yang menjadi tujuan dalam pembahasan penelitian ini. Dalam kajian tasawuf para ulama membuat sebuah metode yang berupa tahapan-tahapan dalam latihan 
rohani guna mendekatkan diri kepada Allah yang terdiri dari tiga tahapan yaitu: takhalli, tahali, dan tajalli. [8]

\section{Metode}

Penelitian ini menggunakan pendekatan deskriptif kualitatif yaitu penelitian yang menguraikan, menggambarkan atau mendeskripsikan, dan memaparkan semua aspek yang bersangkutan dengan penelitian secara detail dalam bentuk kata-kata dan bahasa. Sumber data dalam penelitian ini berupa novel yaitu Sastra Jendra Hayuningrat Pangruwating Diyu yang terbit tahun 2012 di Yogjakarta dengan penerbit LKis Yogyakarta. Berdasarkan sumber data tersebut, ditemukan kata-kata, kalimat, dan paragraf yang menjadi data kajian. Adapun teknik pengumpulan data yang digunakan adalah studi kepustakaan, baca, dan catat.

Adapun teknik analisis data adalah hermeneutika dengan langkah-langkah, yaitu (1) membaca dengan cermat terhadap sumber data penelitian yang berupa novel; (2) melakukan pemilihan sumber data sebagai data penelitian; (3) mengumpulkan data tambahan yang penelitian; (4) menganalisis data penelitian secara cermat; dan (5) merumuskan simpulan penelitian yang telah dilakukan.

\section{Hasil dan Pembahasan}

Novel merupakan salah satu alat yang bisa digunakan dalam menyampaikan sebuah pesan kepada pembacanya. Pesan tersebut bisa berupa nilai-nilai spiritual seperti yang ada dalam novel SJHPD. Novel ini menceritakan tokoh Sudrun yang sedang melakukan perjalanan spiritual untuk mendekatkan diri pada Allah yang dalam ilmu tasawuf disebut salik. Perjalanannya sebagai seorang salik menyebabkan ia bertemu dengan berbagai macam karakter manusia sebagai ujian baginya dalam menapaki jalan salik. Selain itu, ia juga bertemu dengan beberapa orang yang akhirnya menjadi gurunya dan menuntunnya sebagai seorang salik dengan melalui tahapan takhalli, tahalli, dan tajalli.

\subsection{Takhalli}

Takhalli adalah tahapan pertama yang harus dilewati oleh seorang salik. Pada tahapan ini seorang salik berusaha untuk membersihkan diri dari segala sifat dan perbuatan tercela. Tahapan ini bertujuan untuk menghindari perbuatan tercela yang bisa menghambat dan menghalangi dalam usaha mendekatkan diri kepada Allah. Usaha membersihkan diri dari sifat dan perbuatan tercela dapat dilihat dalam kutipan berikut ini:

"Mari Mas Sudrun, minum, sekedar penghormatan!'.... "Wah, maaf, saya tidak minum," kata saya mengelak meski dada saya terasa panas karena tersinggung diajak mabuk-mabukan. (SJHPD, p. 128)

Kutipan di atas menggambarkan bahwa sang Salik menghindari perbuatan tercela dengan menolak ajakan temannya untuk minum-minuman yang memabukkan. Minum-minuman yang memabukkan bisa membuat seseorang menjadi jauh dengan Allah sehingga hal ini harus dihindari agar usaha mendekatkan diri kepada Allah bisa terwujud. Selain menolak minum- 
minuman keras Sudrun juga menahan rasa marah di dadanya. Hal ini bisa dilihat dalam kutipan berikut ini:

"Satu gelas saja, Mas, untuk penghormatan hari raya, ”... didesak seperti itu saya naik darah. Tapi saya tidak ingin terjadi ribut-ribut meski dada saya sudah hampir meledak karena dipenuhi keinginan untuk menghajar mereka. (SJHPD, p. 128)

Kutipan di atas menunjukan bahwa Sudrun berusaha menahan amarahnya ketika didesak untuk minum karena tidak ingin terjadi keributan. Marah merupakan salah satu perbuatan tercela yang harus dihindari oleh seorang salik. Selain menahan marah karena didesak untuk minum, Sudrun juga menahan rasa marahnya ketika wajahnya disamakan dengan Hanoman dan Phitecantrophus Erektus oleh sahabatnya yang bernama Debendra. Hal ini dapat dilihat dalam kutipan sebagai berikut:

"Diamput! Saya misuh-misuh dalam hati karena disamakan oleh Debendra dengan Hanoman dan Phitecantrophus Erectus. Hampir saja darah dalam otak saya menyembur dan menggelapkan mata saya. Sungguh, saya hampir saja meninju muka Debendra.... tapi saya segera menahan diri setelah melihat kepolosan Debendra....." (SJHPD, p. 169)

Kutipan di atas menunjukan betapa hati Sudrun sangat marah dan ingin memukul wajah Debendra, namun ia menahan diri setelah melihat kepolosan Debendra. Sebagai seorang salik yang baru menapaki tahap Takhalli maka sifat pemarah harus dihindari agar hati menjadi bersih. Dalam hal menghindari sifat-sifat tercela agar tidak disesatkan oleh Allah dalam usaha mendekat diri kepada-Nya, maka seorang salik harus menghindari sifat-sifat iblis yang mengejawantah di dalam dirinya.Hal ini dapat kita lihat dalam kutipan berikut ini:

"....tetapi, saya juga tidak boleh berprasangka buruk bahwa saya akan disesatkan Allah. Yang pasti, sekarang ini, bagaimanapun saya harus selalu sadar untuk senantiasa berjuang sekuat tenaga menghindari sifat-sifat iblis yang mengejawantah dalam nafs saya sambil terus saya bermohon agar terus menerus beroleh rahmat dan hidayah-Nya." (SJHPD, p. 165)

Berdasarkan kutipan di atas Sudrun berusaha untuk menghindari sifat-sifat iblis yang telah mengejawantah dalam dirinya sambil berdoa memohon kepada Allah agar memperoleh rahmat dan petunjuk-Nya. Dengan memperoleh petunjuk-Nya maka seorang salik tidak akan tersesat dalam mencari jalan mendekatkan diri kepada Allah.

\subsection{Tahalli}

Setelah melewati tahapan Takhalli maka seorang salik harus melewati tahapan kedua yaitu Tahalli. Setelah seorang salik bersih dari sifat dan perbuatan tercela maka langkah selanjutnya yaitu mengisi kehidupannya dengan sifat dan perbuatan terpuji sebagai tahapan selanjutnya yaitu tahalli. Selain itu, pada tahapan ini seorang salik harus mengisi kehidupannya dengan ketaatan yang tinggi dalam menjalankan perintah agama. Dalam SJHPD salah satu perbuatan terpuji terlihat dalam tokoh Sudrun. Sudrun adalah seorang salik yang sedang melakukan latihan rohani dalam mendekatkan diri kepada Allah. Salah satu perbuatan 
terpuji Sudrun yaitu menolong seekor anjing yang sedang dilempari oleh anak-anak. Hal ini dapat dilihat dalam kutipan sebagai berikut:

"Melihat nasib anjing kurus yang celaka itu, tiba-tiba saja hati saya runtuh. Entah bagaimana awalnya, mendadak saja air mata saya jatuh, hati saya terasa melumer bagai salju mencair membentuk titik-titik air di kelopak mata saya." (SJHPD, p. 303)

Dari kutipan di atas menggambarkan seorang salik yang memiliki rasa kasihan kepada sesama makhluk hidup meskipun makhluk tersebut hanya seekor anjing yang kurus. Padahal dalam beberapa pendapat ulama anjing merupakan salah satu binatang yang najis namun hal ini tidak menyurutkan semangat sang salik untuk menolong anjing tersebut. Hal ini bisa kita lihat dalam kutipan berikut:

"Dia najis!" seru anak itu menuding, "Dia tadi masuk halaman surau dan mengendus celana saya. ... Sadar bahwa saya tidak akan bisa mencegah anak-anak itu agar tidak membunuh anjing celaka itu, saya akhirnya tidak memiliki pilihan lain kecuali memberikan sekadar uang kepada mereka sebagai ganti pembeli anjing celaka itu, meski saya sendiri tentunya emoh memeliharanya." (SJHPD, p. 304)

Kutipan di atas menggambarkan bahwa sang salik memiliki perbuatan terpuji dengan menolong anjing tersebut meskipun ia sendiri enggan untuk memeliharanya karena anjing tersebut najis. Selain menolong anjing, sang salik juga menolong bayi yang dibuang oleh orang tuanya di pinggir jalan. Hal ini bisa kita lihat dalam kutipan berikut ini:

"Pada saat pandangan mata saya menyapu trotoar di bawah tiang lampu jalan darah saya mendadak tersirat sewaktu saya dapat di bungkusan selimut lusuh yang ternyata berisi seorang bayi. ...Akhirnya saya memutuskan bahwa apapun yang terjadi saya harus menolong bayi mungil kurus yang malang itu.” (SJHPD, p. 306308)

Kutipan di atas menggambarkan ketika sang salik sedang berjalan di pinggir jalan lalu ia melihat seorang bayi yang terbungkus selimut lusuh. Bayi malang dan tak berdosa itu kemudian ia tolong tanpa mempertimbangkan apapun nanti yang akan terjadi karena dengan menolong bayi tersebut tentunya sang salik harus menanggung semua kebutuhan bayi tersebut mulai dari tempat tinggal, makanan, ASI, dan lain sebagainya. Namun, sang salik tidak mempedulikan hal itu dan tetap menolong bayi tersebut.

\subsection{Tajalli}

Tajalli merupakan tahapan di mana seorang hamba merasakan adanya rasa ketuhanan yang tinggi sampai lenyapnya sifat-sifat kemanusiaan pada dirinya dan munculnya kesadaran rabbani. [9] Setelah melewati tahapan tahalli dan takhalli maka seorang salik sampai pada tahap tajalli, yakni membangun integrasi diri sebagai pribadi yang telah merasakan kehadiran Allah Jalla Jalaluhu dalam setiap gerak langkahnya.[10] Tahapan ini merupakan puncak yang dicita-citakan oleh seorang salik. Dalam SJHPD tahapan tajalli dialami oleh tokoh Sudrun yang bisa kita lihat dalam kutipan berikut ini: 
"Beberapa jenak kemudian saya merasakan seolah-olah berdiri di suatu hamparan Biru terang kehijauan yang membentang luas tanpa batas. Entah apa yang terjadi saya merasakan betapa tubuh jiwa saya telah hilang dan saya tinggal menjadi saya dengan tubuh jiwa dan bercahaya." (SJHPD, p. 466)

Kutipan di atas menggambarkan bahwa sang salik mengalami sebuah pengalaman spiritual dimana ia merasakan dirinya hilang dan lenyap (sirna) namun ia merasa kekal abadi dalam realitas yang tertinggi karena lenyapnya sifat-sifat kemanusiaan dan munculnya kesadaran akan kehadiran Allah dalam setiap gerak langkahnya.

\section{Simpulan}

Berdasarkan uraian tersebut, dapat disimpulkan bahwa dalam novel Sastra Jendra Hayuningrat Pangruwatig Diyu karya Agus Sunyoto menceritakan tokoh utama yang bernama Sudrun dalam perjalanannya mendekatkan diri kepada Allah yang akhirnya bertemu dengan orang-orang yang membimbingnya dalam menemukan jalan mendekatkan diri kepada Allah. Dalam novel tersebut terdapat tahapan-tahapan dalam latihan rohani yang meliputi takhalli, tahali, dan tajalli.

\section{Referensi}

[1] Al-Jurjāni AIM. At-Ta'rifat. Beirut: Dar al-Kutub al-Ilmiyyah. 1983. h.116.

[2] Al-Banjari MN. Al-Durr an-Nafis. Pulau Pinang: Maktabah wa Matba'ah al-Ma'arif. h. 8.

[3] Manam MA. Salik dan Majdhub dari PersPektif Ilmu Tasawuf . JURNAL ISLAM \&Masyarakat Kontemporari. 2008. Vol 1. 59-69.

[4] Hadziq A. Rekonsiliasi Psikologi Sufistik dan Humanistik. Semarang: RaSAIL, 2005

[5] Rohman, A. Manunggaling Kawula Gusti Dalam Novel Sastra Jendra Hayuningrat Pangruwating Diyu karya Agus Sunyoto (Analisis Semiotika Roland Barthes). 2020.

[6] Tirsan. Religiusitas Dalam Novel "Sastra Jendra Hayuningrat Pangruwating Diyu" Karya Agus Sunyoto. Edu-Kata. 2015. Vol 2. No. 2

[7] Hartati Y. Pencarian Kebenaran Dalam Novel Sastra Jendra Hayuningrat Pangruwating Diyu Karya Agus Sunyoto: Analisis Semiotik Dan Implementasinya Dalam Pembelajaran Sastra Di SMA. 2016.

[8] Nasution AB, Siregar RH. Akhlak Tasawuf Pengenalan Pemahaman dan Pengaplikasian Disertai dan Tokoh-Tokoh Sufi.Jakarta: PT. Raja Grafindo Persada; 2013. h. 72-75

[9] Istiani N, Islamy A. Objektifikasi Nilai-nilai Psiko-Sufistik dalam Pendidikan Spiritual. HIKMATUNA Journal for Integrative Islamic Studies. 2018. Vol 4. 234-245.

[10] Fauzi, A. Psikosufistik Pendidikan Islam Dalam Perspektif Pemikiran Syekh Ibnu Atha'illah. Intelektual Jurnal Pendidikan dan studi Islam. 2018. Vol. 8. 229-239.

[11] Sunyoto, A. Sastra Jendra Hayuningrat Pangruwating Diyu.Jogjakarta: LKis Yogyakarta. 2012 